\title{
Revisión de lectura de una insCRIPCión romana de Piñel de Abajo (VALLADOLID. HEP 9, 1999, 604)
}

JUAN MANUEL ABASCAL PALAZÓN (10

Área de Historia Antigua. Universitat d'Alacant. juan.abascal@ua.es

En el valle medio del río Duero y en su margen derecha, pocos kilómetros al norte del cauce fluvial y de las localidades de Pesquera y Peñafiel, se encuentra Piñel de Abajo, un enclave conocido en la bibliografía como lugar de origen de tres inscripciones funerarias romanas. Unos kilómetros al norte de Piñel de Abajo, entre los ríos Esgueva y Duero, discurre el arroyo Jaramiel, que da nombre a una dehesa y caserío de Jaramiel de donde parecen proceder los epígrafes ${ }^{1}$.

El primer de ellos fue dado a conocer por A. Recio hace casi medio siglo (Recio 1971: 445-457) y luego por los editores del conjunto provincial (Mañanes y Solana 1999: 32-33 n. ${ }^{\circ} 16$ ), en ambos casos con una lectura poco satisfactoria, pues el difunto se llamaba en realidad Bodogenus, como se han ocupado de poner de manifiesto algunos de los editores posteriores (De Bernardo y Sanz 2009: 230). De la misma dehesa de Jaramiel, del lugar denominado "El Llano Castillo" procede un segundo fragmento epigráfico (Carretero et al. 1994: 356-358 n. ${ }^{\circ}$ 3; HEp 6, 1996, 989), conservado en el Museo de Valladolid, que formaba parte de una estela que ha perdido una gran parte del texto (Mañanes y Solana 1999: 34-35 n. ${ }^{\circ}$ 17; $\operatorname{HEp} 9,1999,605)$.
El tercer monumento, del que voy a ocuparme, es una estela que se encuentra empotrada a ras de suelo en la fachada exterior de la casa n. ${ }^{\circ} 35$ de la calle Real de Arriba en Piñel de Abajo. Fue dada a conocer en 1994 (Carretero et al. 1994: 353-356 n. 2; HEp 6, 1996, 988), en 1999 (Mañanes y Solana 1999: 29-32 n. ${ }^{\circ}$ 15; HEp 9, 1999, 604) y en 2002 (Hernández 2002: 102 n. ${ }^{\circ} 11$ ). Las dificultades de lectura de esta pieza son máximas debido a la presencia de restos de cemento en la parte inferior y en el perímetro superior, lo que afecta a alguna letra y a la decoración de la cabecera.

Mientras que la estructura y decoración de la estela habían sido dadas a conocer ya con suficiente detalle, las lecturas publicadas hasta la fecha no permiten una interpretación coherente del texto, por lo que realicé una nueva inspección del mismo el 30 de junio de 2018. Los resultados son los que presento en estas líneas. La parte visible del monumento, que por su parte inferior está empotrado en la acera y por arriba está abrazado con cemento, mide (61) x (49) x ? cm. El texto está grabado en una cartela rebajada de (35) x $40 \mathrm{~cm}$, con letras cuya altura oscila entre 2 y $3 \mathrm{~cm}$. La $A$ carece en todos los casos de travesaño horizontal. 


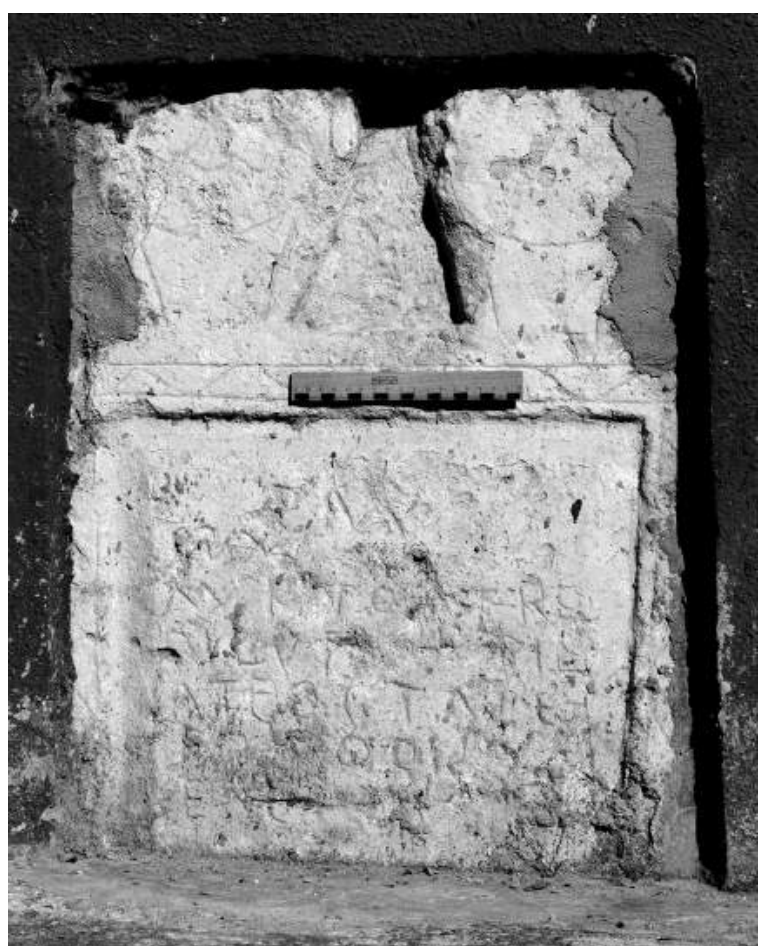

Fig. 1: Estela de Piñel de Abajo.

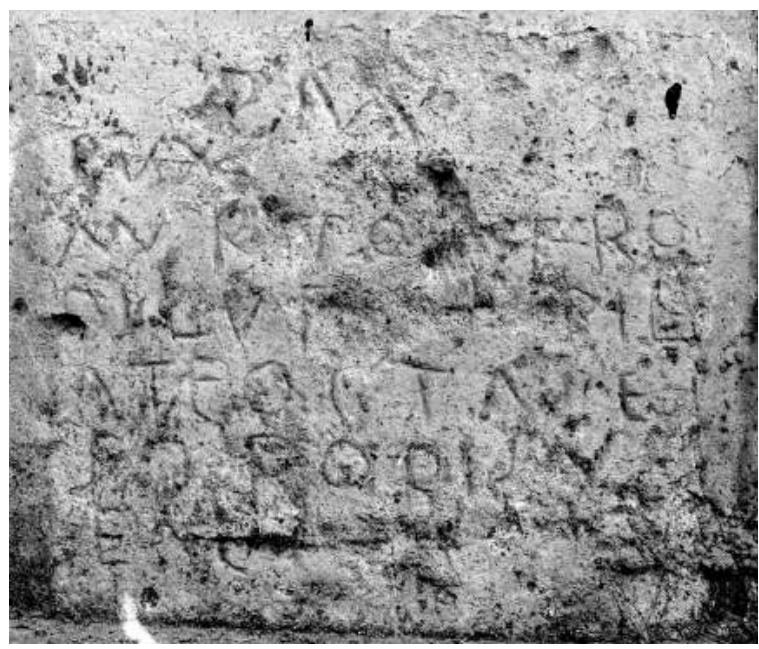

Fig. 2: Detalle del texto en la estela de Piñel de Abajo.

En el primer renglón (fig. 1, 3) sólo se distingue la invocación a los dioses Manes, escrita con una $D$ muy pequeña y una $M$ ancha y en posición oblicua. En el segundo, no quedan otras letras que las tres ya vistas con anterioridad, es decir, $P V X$, todas ellas muy juntas entre sí y colocadas en la parte izquierda de la línea; el resto del

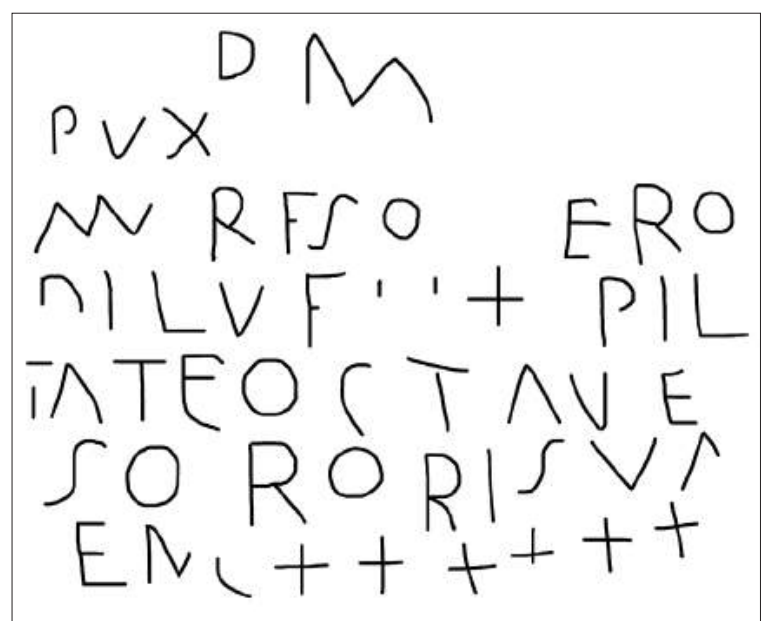

Fig. 3: Restos de letras en la inscripción de Piñel de Abajo.

renglón nunca fue utilizado y está completamente libre de rasgos de escritura. Ninguna de esas tres letras está unida con otra, por lo que hay que descartar los nexos propuestos por los primeros editores (Carretero et al. 1994: 353-356 n. ${ }^{\circ}$ 2) que dieron lugar a un nombre personal Pivax(a) que no existe.

El tercer renglón comienza con el praenomen Manius (también usado como nomen gentile; $c f$. Schulze 1904/1991, 469), escrito en la forma habitual, es decir, como una $M$ con un apéndice oblicuo por la derecha. Cada vez es mejor conocido el uso de este praenomen en las inscripciones romanas de Hispania (Abascal et al. 2011: 88), por lo que no debe extrañar su presencia aquí. A continuación se lee una $R$ y quedan los rastros de una $E$ que precede a una $S$ muy tumbada pero aún intacta y a una $O$, con lo que estamos ante la voz Reso, dativo del cognomen latino Resus. En el centro de la línea hay una zona dañada en la que pudo haber algún elemento de interpunción. A su derecha, sin nada que las preceda, se ven bien las letras $E R O$, que pertenecen a la misma palabra que los cuatro caracteres iniciales del cuarto renglón: aquí se ve una $P$ con el ojo sin cerrar y el pie dañado por un golpe, seguida de los caracteres $I L V$. En consecuencia, entre los renglones tercero y cuarto hay que leer $E R O$ $P I L V$, es decir, $<H>$ erop $<h>$ ilu $<s>$, un conocido $c o g$ nomen de origen griego (Solin 2003: 73); es muy probable, como se ve por la estructura del texto, que aquí hubiera que esperar un genitivo $<H>$ erop $<h>i l\{i\}$ para entender la filiación del difunto. A continuación, aún en la cuarta línea, se ve bien una $F$ seguida de una zona dañada en la que sólo se distingue el extremo superior de 
dos astas verticales, con lo que hay que entender fil(io), y una cruz griega perfectamente grabada. Entre el final del cuarto renglón y el comienzo del quinto se lee PILTATE, una forma irregular del bien conocido nombre griego $P<h>$ iltate (Solin 2003: 959). Ese quinto renglón se completa con la voz OCTAVE, es decir, una forma irregular del cognomen en dativo Octav $<a>e$. La sexta línea y el inicio de la séptima han sido leídos de forma unánime por todos los editores y allí dice, efectivamente, SORORI $S V A / E$. Pero detrás de la $E$ sólo se ve un probable nexo $A N$, aunque la $A$ carece de travesaño horizontal, y el pie de una $L$, identificación que sólo es posible si se compara esa letra con la primera $E$ del quinto renglón. La sexta línea, como ya vieron los editores anteriores, se completa con seis cruces griegas consecutivas que sólo manifiestan el horror vacui del grabador.

A tenor de lo anterior, el texto dice lo siguiente:

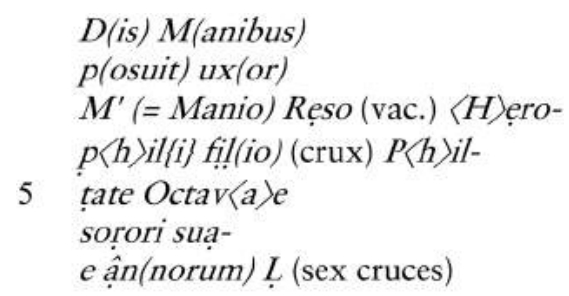

4 Al inicio del renglón se lee PILV en vez de PILI. Variantes:

D(is) M(anibus) / Pivax(ae) / Ma(nius) Ripo[-- -]

Froldilu f(ilius) [- - - Jpi Llatro Cotase I sorori suale an(norum) $L++++++$

Carretero et al.

D(iis) M(anibus) / P(osuit?) ux(or?) / m[a]rito [-] TRO / AILVE f(ilio? ) [- - ] TRIL/ [-]ATRO OTASE I sorori suale an(norum) $L++++++$

Mañanes y Solana.

D(iis) M(anibus) / pi(a) ux(or) / murito (sic) [-] TRO / DILV R[- - - ]L I ATRO(nis) f(ilio) Octavie I sorori suale an(norum) $L$

Hernández

Es decir, los difuntos citados en el texto son dos. Se trata de Manius (- - ) Resus, hijo de Herophilus, al que le dedica el epitafio su anónima esposa; y de Octava, hermana de Philtate, de la que se indica la edad del fallecimiento.
En el caso del primer difunto hay que imaginar que Manius es un praenomen y no el nomen gentile homónimo (Schulze 1904/1991: 469; Solin y Salomies 1988: 112), bien documentado incluso en Hispania (Abascal 1994: 179) pero que suele escribirse in extenso y no en la forma abreviada. En todo caso, no se puede descartar ninguna de las dos opciones. Si Manius es aquí un praenomen, el difunto poseía la plena ciudadanía y se omitió su nomen gentile. La difunta, enterrada junto a él con una misma estela, es identificada con un nombre único y podría ser tanto una esclava como una liberta de nomen omitido. Esta posible -y probable-doble omisión del nomen hace suponer que era el mismo en los dos casos y sobradamente conocido en el ámbito local, por lo que podría tratarse de dos libertos de un mismo individuo que no aparece identificado en el texto. La omisión del gentilicio es un fenómeno bien conocido en inscripciones de miembros de las élites de las ciudades y del estado, especialmente en el s. I de la Era (Salomies 1988: 125-129); el fenómeno se observa también en otros textos posteriores pero no es habitual en contextos serviles o libertinos.

El cognomen latino Resus, no recogido en la obra de Kajanto, aparece en inscripciones de Lugdudum (CIL XIII 2260), Puteoli (Q. Attius Resus, CIL X 2122), Cerdeña (Mattius Resus, CIL X 7816), Milán ( $A E$ 1990, 768a-b) e incluso en la provincia de Africa (Mesuleolus Resus, CIL VIII 9815), pero era desconocido hasta el presente en Hispania.

Más frecuente es el cognomen griego Herophilus (Solin 2003: 73), escrito también como Heropilus (Ti. Iulius Heropilus, CIL VI 15517; Heropilus, CIL XV 5254a y $\mathrm{b}$ en una marca de aretina). A los casos conocidos en Italia (L. Pontius Herophilus en CIL VI 24722, C. Trausius C. l. Heropilus en CIL VI 27569 [= 5635], P. Istumennius P. l. Herophilus, en NSA 1914, 380 n. ${ }^{\circ} 23$, etc.) hay que unir dos testimonios en la Baetica, uno de ellos en Arcos de la Frontera ([-. Tere]ntius [He]rophilus en CIL II 1363) y el otro en Anticaria (Sex. Peducaeius Sex. fil. Herophilus en CIL II²/5, $743=$ II 180b*). A ellos hay que añadir un tercer testimonio, procedente de Ávila, en donde parece identificarse a un $<H>$ ero[ph]ilus (HEp 13, 2003/04, 50).

Lo mismo puede decirse del cognomen griego Philtate (Solin 2003: 959), con 15 testimonios muy repartidos, de los que dos proceden de Hispania. El primero de ellos se encuentra en una inscripción de Sagunto $\left(C I L \mathrm{II}^{2} / 14\right.$, $509=$ II 3929) y el segundo -en la forma Philtates - se lee en una conocida inscripción de Lugo $(E E$ 8.2, 311) que 


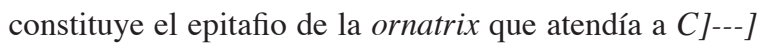
Cattunilla, una dama de origen turinés (Degrassi 1978: 51-56), que debió ser la esposa de un alto funcionario romano (Alföldy 2001: 233-238, con más bibliografía; AE 2001, 1213; HEp 11, 2001, 320).

Respecto al cognomen Octava, Kajanto ya registró hace medio siglo varios testimonios del masculino Octavus (Kajanto 1965: 293; Solin 2005: 174) pero sólo uno del femenino Octava (Pomponia Octava en CIL VI 24669, de Roma); a esa magra relación viene a sumarse este ejemplo.

La invocación inicial sugiere fechar el monumento en el s. II. Hay que tener en cuenta que la paleografía, manifiestamente irregular y debida a una mano inexperta, no puede emplearse aquí como criterio de datación.

\section{NOTA}

1. Este trabajo se ha realizado en el marco del proyecto de investigación Sociedad romana y hábito epigráfico en la Hispania citerior, HAR2015-65168-P (MINECO/FEDER), subvencionado por el Ministerio de Economía y Competitividad del Gobierno de España. Las imágenes son obra del autor del texto. Los paralelos no hispanos que se citan en este texto han sido tomados de la base de datos Clauss/Slaby (http://www. manfredclauss.de), consultada el día 7 de julio de 2018. Quiero agradecer a Manfred Clauss y a sus colaboradores el esfuerzo por mantener viva esa base de datos que sostiene de forma eficaz la edición epigráfica en nuestros días.

\section{BIBLIOGRAFÍA}

ABASCAL, J. M. (1994): Los nombres personales en las inscripciones latinas de Hispania, Murcia.

ABASCAL, J. M.; ALFÖLDY, G.; CEBRIÁN, R. (2011): Segobriga V. Inscripciones romanas (1986-2010), Madrid.

ALFÖLDY, G. (2001): Eine clarissima femina in Lucus Augusti, ZPE 136, 233-238 (Versión española en id., Provincia Hispania superior, A Coruña 2002, 81-91).

CARRETERO, S.; SAN MIGUEL, L. C.; ARRANZ, J. A. (1994): Hallazgos epigráficos romanos de la dehesa de Jaramiel Alto (Piñel de Abajo, Valladolid), V Congreso Internacional de Estelas funerarias, Soria, 349-359.

DE BERNARDO, P.; SANZ, C. (2009): Nueva estela funeraria romana, con onomástica céltica, de Padilla de Duero (Peñafiel, Valladolid), BSAA Arqueología 75, 223-242.

DEGRASSI, A. (1978): Un torinese relegato a Lucus Augusti della Spagna, Atti del I Congresso Internazionale di Archeologia dell'Italia settentrionale, Torino, 51-56 ( = Un turinés relegado a Lucus Augusti (España), Boletín de la Comisión Provincial de Monumentos Históricos y Artísticos de Lugo 9 , n. $\left.{ }^{\circ} 85-86,1978,298-303\right)$.
HERNÁNDEZ GUERRA, L. (2002): Indigenismo y romanización de la provincia de Valladolid, Valladolid.

KAJANTO, I. (1965): The Latin Cognomina (Societas Scientiarum Fennica. Commentationes Humanarum Litterarum 36, 2). Helsinki.

MAÑANES, T.; SOLANA, J. M. (1999): Inscripciones de época romana de la provincia de Valladolid, Valladolid.

RECIO, A. (1971): Una antigua inscripción sepulcral de la dehesa de Jaramiel, en la provincia de Valladolid, BSEAA 37, 445-457.

SALOMIES, O. (1988): Epigraphische Beiträge, Arctos 22, 113-132.

SCHULZE, W. (1904/1991): Zur Geschichte lateinischer Eigennamen. Mit einer Berichtigungsliste zur Neuausgabe von $O$. Salomies, Zürich-Hildesheim (ed. original de 1904).

SOLIN, H. (2003): Die griechischen Personennamen in Rom. Zweite, völlig neu bearbeitete Auflage I-III, Berlin-New York.

SOLIN, H. (2005): Analecta Epigraphica, Arctos 39, 159-198.

SOLIN, H.; SALOMIES, O. (1988): Repertorium nominum gentilium et cognominum Latinorum, Hildesheim-ZürichNew York. 